\section{BMJ Open Respiratory Research}

\title{
Long-term outcomes following severe COVID-19 infection: a propensity matched cohort study
}

Joanne McPeake (D , , ${ }^{1,2}$ Martin Shaw, ${ }^{1,2}$ Pamela MacTavish, ${ }^{1}$ Kevin G Blyth, ${ }^{1,3}$ Helen Devine, ${ }^{1}$ Gillian Fleming, ${ }^{4}$ Justine Griffin, ${ }^{1}$ Lisa Gemmell, ${ }^{1}$ Pauline Grose,${ }^{1}$ Mark Henderson, ${ }^{1}$ Philip Henderson, ${ }^{1,2}$ Lucy Hogg, ${ }^{4}$ Kirstin King, ${ }^{1}$ lain Mclnnes, ${ }^{5}$ Peter O'Brien, ${ }^{6}$ Kathryn Puxty, ${ }^{1,2}$ Callum Rainey, ${ }^{6}$ Varun Sharma, ${ }^{1}$ Malcolm Sim, ${ }^{1,2}$ Laura Strachan, ${ }^{1}$ Stefan Siebert, ${ }^{7}$ Tara Quasim ${ }^{1,2}$

\section{ABSTRACT}

Background There are limited data describing the longterm outcomes of severe COVID-19. We aimed to evaluate the long-term psychosocial and physical consequences of

Methods We conducted a multicentre observational cohort study; between 3 and 7 months posthospital discharge, patients who had been admitted to critical care due to severe COVID-19 were invited to an established recovery service. Standardised questionnaires concerning emotional, physical and social recovery, including information on employment, were completed by patients. Using propensity score matching, we explored outcomes between patients admitted to critical care with and without COVID-19, using data from the same recovery programme.

Results Between July 2020 and December 2020, 93 patients who had been admitted to critical with COVID-19 participated. Emotional dysfunction was common: $46.2 \%$ of patients had symptoms of anxiety and $34.4 \%$ symptoms of depression. At follow-up $53.7 \%$ of previously employed patients had returned to employment; there was a significant difference in return to employment across the socio-economic gradient, with lower numbers of patients from the most deprived areas returning to employment $(p=0.03) .91$ (97.8\%) COVID-19 patients were matched with 91 non-COVID-19 patients. There were no significant differences in any measured outcomes between the two cohorts.

Interpretation Emotional and social problems are common in survivors of severe COVID-19 infection. Coordinated rehabilitation is required to ensure patients make an optimal recovery.

\section{Glasgow, UK}

${ }^{4}$ NHS Fife, Kirkcaldy, UK

${ }^{5}$ University of Glasgow, College of Medical, Veterinary and Life Science, Glasgow, UK ${ }^{6} \mathrm{NHS}$ Ayrshire and Arran, Ayr, UK

${ }^{7}$ Institute of Infection, Immunity and Inflammation, University of Glasgow, Glasgow, UK

Correspondence to Dr Joanne McPeake; joanne.mcpeake@glasgow. ac.uk

The COVID-19 pandemic has had a profound impact on critical care services. ${ }^{12}$ Of those patients who require acute hospitalisation, $14 \%-18 \%$ require admission to a critical care unit. ${ }^{3}$ The clinical presentation of COVID-19 severe COVID-19 for patients.

\section{Key messages}

Following severe COVID-19 infection, patients commonly experience emotional problems such as anxiety and depression.

- In this cohort study, patients residing in the most deprived communities were less likely to return to employment, in comparison to those from the least deprived communities.

Coordinated rehabilitation is required to ensure that both patients and family members make an optimal recovery.

on hospital visitation during often protracted critical care and hospital stays. ${ }^{56}$

Patients who have been critically ill are at high risk of developing physical, psychosocial and cognitive problems following discharge from hospital. ${ }^{7-11}$ These postdischarge issues are known to have a negative influence on societal reintegration for the patient, as well as impacting their close family members. ${ }^{12} 13$ However, there are minimal data describing the long-term outcomes of those who have been severely ill due to COVID-19, and the impact that this will have on wider social outcomes such as return to employment.

The aims of this multicentre cohort study were twofold: (1) Understand the long-term psychosocial and physical consequences, including impact on employment, of severe COVID-19 infection and (2) Explore if critically ill COVID-19 survivors have unique long-term outcomes, in relation to patients admitted to critical care without COVID-19. and its sequelae make delivery of personcentred care challenging, with limited interaction with family members due to restrictions

\section{METHODS}

\section{Design}

We undertook a multicentre, prospective observational cohort study. Results are reported per the Strengthening the Reporting 
of Observational Studies in Epidemiology (STROBE) guidelines. ${ }^{14}$ All patients provided consent.

We compared the incidence of post hospital problems in patients with a diagnosis of severe COVID-19 pneumonia (COVID-19 cohort) versus critically ill patients without COVID-19 pneumonia (non-COVID-19 cohort) using a propensity score matching analysis.

\section{Participants}

\section{COVID-19 cohort}

Patients who had been admitted to one of seven critical care units, in five hospitals across Scotland between March 2020 and May 2020 with SARS-CoV-2(or a high clinical suspicion of SARS-CoV-2) were invited to a pre-existing Intensive Care Unit (ICU) rehabilitation programme, 3-7 months posthospital discharge. These sites represent a mix of inner-city tertiary referral hospitals and district general hospitals. A critical care unit in this study delivered either level two or three care, as defined by the UK Intensive Care Society. ${ }^{15}$

\section{Non-COVID-19 cohort}

Patients who had been admitted to one of five critical care units, in five hospitals across Scotland, were invited to the same ICU rehabilitation programme (8-15 weeks posthospital discharge), between May 2016 and October 2018. In total, 206 patients consented to inclusion in this cohort. Due to missing data, we undertook propensity score matching with 182 patients. Information on missing data is shown in online supplemental file S1.

\section{Setting}

All patients were recruited from an established critical care follow- up programme. Details of the rehabilitation programme, Intensive Care Syndrome: Promoting Independence and Return to Employment (InS:PIRE), have been published previously. ${ }^{16}{ }^{17}$ Briefly, patients are reviewed by the critical care multidisciplinary team, including nurses, medical staff, pharmacists and physiotherapists, after discharge from critical care. Onward referral to other services such as welfare support, dietetics and clinical psychology are available. The InS:PIRE service also includes specific support about return to employment and vocational rehabilitation.

Due to hospital attendance restrictions in place across the UK, all clinic consultations for the COVID-19 cohort took place virtually or by telephone. Due to the long-term respiratory complications which are predicted in survivors of severe COVID-19, the COVID-19 cohort were also part of an integrated respiratory referral pathway.

\section{Data collection}

All patients were invited to take part in this study during their appointment (in-person for the non-COVID-19 cohort, and virtually for the COVID-19 cohort). If agreeable to research participation, the patient was contacted by a member of the research team (also members of the direct clinical care team) and data for this study was obtained. All data collection was undertaken via telephone or through postal completion of the questionnaires for the COVID-19 cohort, or in-person for the non-COVID-19 cohort. Study outcome measures were obtained before any referrals arising from the consultation had taken place (ie, vocational rehabilitation).

Patient demographic and clinical data was obtained from clinical notes and discharge summaries. Comorbidity data (including mental health data) were obtained from medical notes and critical care admission records. Critical care length of stay was taken for the highest level of care, during the first critical care admission only.

The Scottish Index of Multiple Deprivation (SIMD) is produced by the Scottish Government as a measure of deprivation, with postcode areas defining data on socioeconomic status. This research split the SIMD into five categories to define socioeconomic status; quintile one represented the most deprived and quintile five the least. ${ }^{18}$

\section{PATIENT AND PUBLIC INVOLVEMENT}

The InS:PIRE service was coproduced with survivors of critical illness and their family members. We designed the intervention and all outcome measures with the previous service users through the creation of a patient and family advisory council. Throughout both the feasibility work and the scale up work of the InS:PIRE programme, priority of the research question, choice of outcome measures, and methods of recruitment were informed by further structured, service user feedback.

\section{OUTCOME MEASURES}

\section{Patient outcomes}

We sought to understand how baseline employment status had been impacted by severe COVID-19 infection. Employment data were collected during the clinical consultation. We used four potential categories for employment status: employed; not employed; retired and unknown. This preplanned analysis specifically sought to delineate the impact of deprivation on return to employment. Employment data were not collected for the non-COVID-19 cohort at this timepoint, thus, was not included as part of the Propensity Score Match analyses.

Health-related quality of life (HRQoL) was measured using the EQ-5D-5L tool (EuroQuality of Life Group). ${ }^{19}$ The measure comprises two sections: a five-question descriptive component which explores health domains (mobility, self-care, ability to undertake usual activities, pain and mental health) and a Visual Analogue Scale about HRQoL. Each of five questions has five possible answers. These answers equate to a five-digit sequence which is then used to determine a Health Utility Score (HUS). In EQ-5D evaluations, a HUS of 1 equates to the best health state possible, 0 with death and a negative HUS equates to a state worse than death. 
Emotional health was measured using the Hospital Anxiety and Depression Score (HADS).$^{20}$ The HADS questionnaire contains 14 statements relating to mood, with 7 statements relating to depression and seven to anxiety. Each statement has four potential options (scored 0-3). Online supplemental file S2 describes the cut-off points utilised for scores obtained from the HADS. Both the HADS and EQ-5D-5L have been recommended as core outcome measures in acute respiratory failure research. ${ }^{21}$ Appropriate licensing requirements were in place for the HADS and EQ-5D-5L.

Information about ongoing pain was obtained via the Brief Pain Inventory (BPI) ${ }^{22}$ Participants identified where the most severe area of pain was, as well as any other painful sites. Using the BPI pain intensity, alongside interference with function (for example household activities, walking, sleeping and mood) was assessed. Each item was rated on an 11-point ordinal scale $(0=$ no pain and $10=$ worst pain). Participants were asked to describe new pain (since hospital discharge) only. Information about symptoms of breathlessness and fatigue were obtained with fixed single questions.

\section{STATISTICAL ANALYSIS}

Analyses was undertaken using R (V.4.0.5). All missing covariates were imputed for analysis using predictive mean matching with the Multivariate Imputation by Chained Equations software package. Each variable with missing values was regressed on all other analysed variables per single imputation. We did not input return to employment data. Information on missing data for both cohorts included in this study is presented in online supplemental file S1. Employment, breathlessness and fatigue data was not available for the nonCOVID-19 cohort.

Continuous variables were expressed as medians and IQR. The Kruskall-Wallis test was used to compare different subgroups and the $\chi^{2}$ test to analyse categorical variables.

Logistic regression was used to examine the impact of deprivation on failure to return to employment. SIMD was encoded in a categorical fashion, which allowed the estimation of a non-linear effect between the sociogradient and return to employment. Based on previous literature in this field and univariable associations, we adjusted for pre-existing multimorbidity, follow-up time, age and critical care length of stay. ${ }^{23}$

Propensity score matching was performed matching for: age; gender; socioeconomic deprivation; hospital site; critical care length of stay; Acute Physiology and Chronic Health Evaluation II (APACHE II); time to follow-up; presence of obesity or mental issue pre-ICU and presence of multimorbidity (two or more comorbidities). The pain/discomfort analysis, which was undertaken with the propensity score matched data, was undertaken using logistic regression, dichotomised at severe pain and above in the EQ-5D-5L scale. Four linear regression models were utilised for the remaining outcomes (EQ-5D-5L HUS, EQ-5D-5L Visual Analogue Scale and HADS). Following the propensity score
198 critical care survivors invited to InS:PIRE

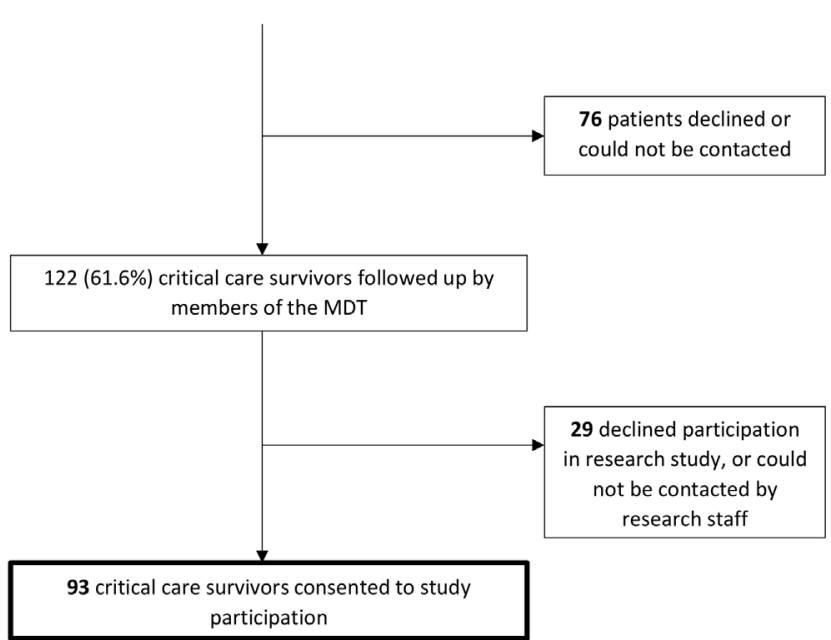

Figure 1 Patient flow through the study (invitation through to participation). InS:PIRE, Intensive Care Syndrome:

Promoting Independence and Return to Employment; MDT, multidisciplinary team.

matching analyses we adjusted for the following variables: age; gender; socioeconomic deprivation; ICU length of stay; APACHE II; time to follow-up; presence of obesity or mental issue pre-ICU and presence of multimorbidity (two or more comorbidities). This approach minimised bias during this stage of analysis. To account for any imputational bias during the modelling and matching process, we undertook multiple imputations (10 imputations alongside 10 iterations).

Covariates for each of the statistical approaches (logistic regression and propensity score matching) were based on univariable associations, previous literature in this field and domain expertise. Although the covariate selection is similar across each of the strategies; the propensity score match modelling includes more covariate adjustment, as a larger sample size facilitated this.

\section{RESULTS}

\section{COVID-19 cohort characteristics}

Across the five sites involved, 198 patients who had a diagnosis of COVID-19 were invited to attend follow-up; 122 $(61.6 \%)$ patients were reviewed and approached about participation in this research; 93 consented to take part (figure 1).

Sixty-one participants $(65.6 \%)$ were male, the median patient age was 59 (IQR:54-67) years and the median hospital length of stay was 22 (IQR: 12-55.7) days. Sixtythree $(67.7 \%)$ patients received invasive ventilation and $18(19.4 \%)$ received renal replacement therapy (table 1$)$. The median time to follow-up was 135 (IQR: 85-181) days following hospital discharge. A description of COVID-19 patients who were invited but did not attend is shown in online supplemental file S3. 


\begin{tabular}{|c|c|}
\hline Characteristic & $\mathrm{n}=93$ \\
\hline Gender, male (\%) & $61(65.6)$ \\
\hline Age, median years (IQR) & $59(54-67)$ \\
\hline Obesity (\%) & $30(32.3)$ \\
\hline Black and minority ethnic (\%) & $4(4.3)$ \\
\hline Smoking (\%) & $7(7.5)$ \\
\hline \multicolumn{2}{|l|}{ Comorbidities } \\
\hline Hypertension (without complications) (\%) & $36(38.7)$ \\
\hline Cardiovascular disease (\%) & $11(11.8)$ \\
\hline Respiratory disease (\%) & $28(30.1)$ \\
\hline Endocrine (including diabetes) (\%) & $23(24.7)$ \\
\hline Liver (\%) & $1(1.1)$ \\
\hline Gastrointestinal (\%) & $12(12.9)$ \\
\hline Mental health (\%) & $12(12.9)$ \\
\hline $\begin{array}{l}\text { Presence of multimorbidity ( } 2 \text { or more } \\
\text { comorbidities) (\%) }\end{array}$ & $47(51.1)$ \\
\hline Hospital length of stay, median, days (IQR) & $22(12-55.7)$ \\
\hline Critical care length of stay, median, days (IQR) & $11.1(5-25.3)$ \\
\hline $\begin{array}{l}\text { Acute Physiology and Chronic Health Evaluation II } \\
\text { Score, median (IQR) }\end{array}$ & $15(10-20)$ \\
\hline Invasive ventilation (\%) & $63(67.7)$ \\
\hline $\begin{array}{l}\text { Continuous positive airway pressure ventilation } \\
\text { (never received invasive ventilation) (\%) }\end{array}$ & $16(17.2)$ \\
\hline $\begin{array}{l}\text { Continuous positive airway pressure ventilation } \\
\text { (also received invasive ventilation) (\%) }\end{array}$ & $11(11.8)$ \\
\hline Renal replacement therapy (\%) & $18(19.4)$ \\
\hline Advanced cardiovascular support (\%) & $35(37.6)$ \\
\hline Proned (\%) & $36(38.7)$ \\
\hline \multicolumn{2}{|l|}{ Socioeconomic status: (SIMD category) } \\
\hline 1 (most deprived) & $30(32.3)$ \\
\hline 2 & $19(20.4)$ \\
\hline 3 & $20(21.5)$ \\
\hline 4 & $8(8.6)$ \\
\hline 5 (least deprived) & $16(17.2)$ \\
\hline \multicolumn{2}{|l|}{ Employment status before admission } \\
\hline Employed (\%) & $67(72)$ \\
\hline Unemployed (\%) & $6(6.5)$ \\
\hline Retired (\%) & $17(18.3)$ \\
\hline Unknown & $3(3.2)$ \\
\hline
\end{tabular}

SIMD, Scottish Index of Multiple Deprivation.

\section{COVID-19 cohort: patient outcomes}

\section{Psychosocial outcomes}

In the COVID-19 cohort, 67 (72\%) patients were employed before admission to critical care, six (6.5\%) were unemployed and 17 (18.3\%) were retired. Pre and post critical illness employment data were not available for three $(3.2 \%)$ patients. The distribution of pre-critical illness employment status across the SIMD quintiles is shown in online supplemental file S4. At the time of follow-up, $36(53.7 \%)$ of those working beforehand had

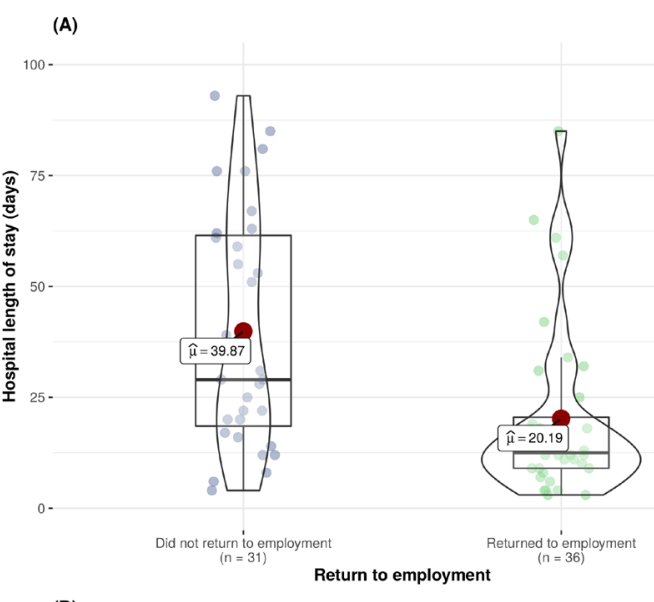

(B)

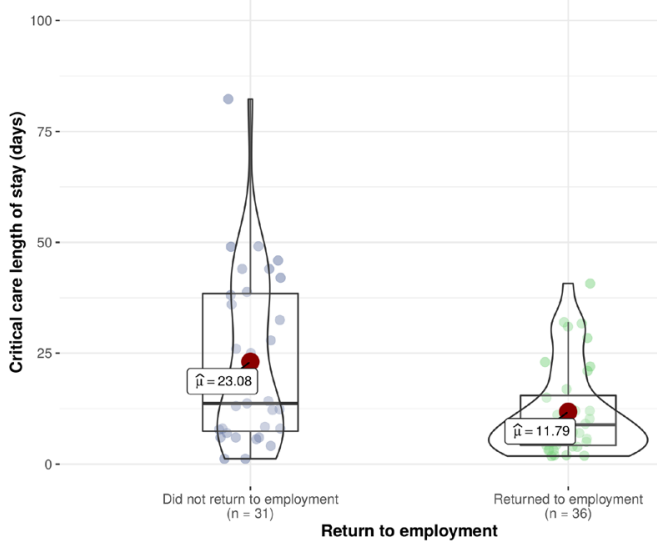

(C)

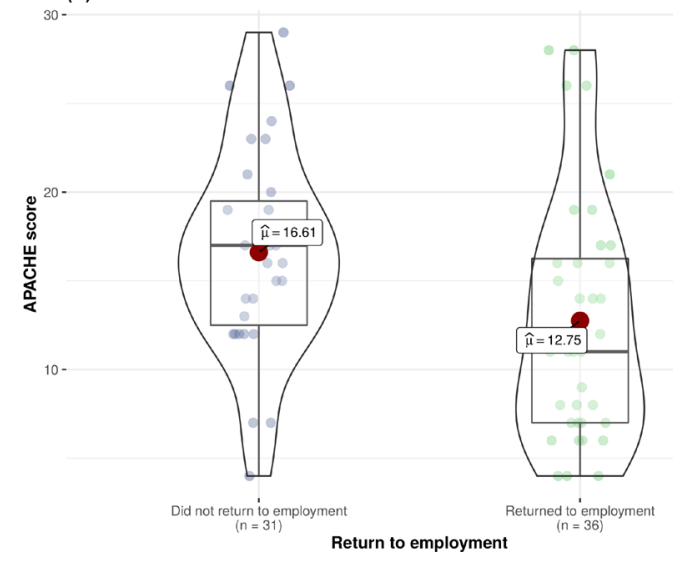

Figure 2 Distribution of hospital (A) and critical care (B) length of stay and APACHE II scores (C) in those returning to, and not returning to employment. APACHE II, Acute Physiology and Chronic Health Evaluation II.

returned to employment, one $(1.5 \%)$ had newly retired and $30(44.8 \%)$ of those who had been employed before critical care had not returned to employment. The six patients who were unemployed before admission, remained unemployed at follow-up.

We undertook a subgroup analysis to explore outcomes in those employed before admission to critical care $(n=67)$. Patients who returned to employment had significantly shorter hospital (12.5 days (IQR: 9.0-22.5) vs 29 days (IQR: $17.5-61.8), \mathrm{p}<0.01)$ and critical care (8.9 days 


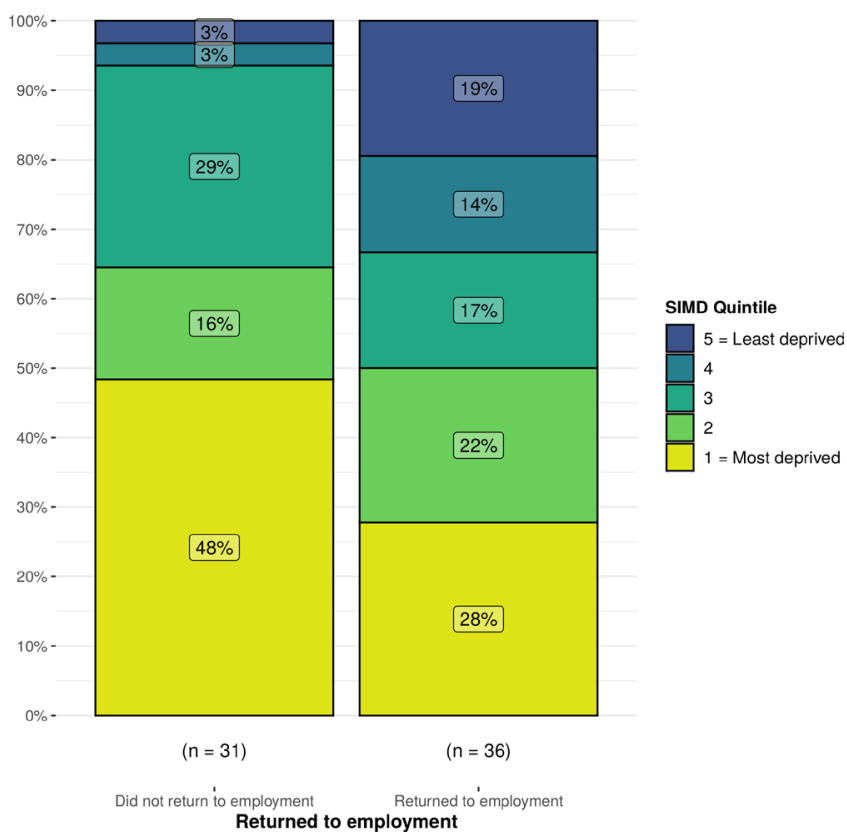

Figure 3 Breakdown in return to baseline employment status across the SIMD quintiles. SIMD, Scottish Index of Multiple Deprivation.

(IQR: 4.1-16.1) vs 13.7 days (IQR: 7.1-38.7), $\mathrm{p}=0.01$ ) stays. Patients who returned to employment also had significantly lower APACHE II scores (11 (IQR:7.0-16.6) vs 17 (12.2-19.8), $\mathrm{p}=0.01$ ) (figure 2 ). In this subgroup analysis, there was a significant difference in return to employment across the socio-economic gradient, with a higher proportion of patients from deprived areas failing to return to employment (SIMD $1=48 \%$ vs SIMD 5=3\%) (figure 3). After adjustment for multimorbidity, follow-up time, age and critical care length of stay, those residing in the most deprived communities were less likely to return to employment in comparison to those from the least deprived communities (OR 0.06; 95\% CI 0.00 to 0.76 , $\mathrm{p}=0.03$ ) (online supplemental file S5).

Twelve $(12.9 \%)$ patients had pre-existing or historical mental health issues at the time of admission to critical care. Measured via the HADS, $43(46.2 \%)$ patients had symptoms of anxiety. Using previously defined cut-offs (online supplemental file S2), $11(25.6 \%)$ patients had symptoms of mild anxiety, $15(34.9 \%)$ moderate and 17 $(39.5 \%)$ severe. Symptoms of depression, measured via the HADS, were reported in $32(34.4 \%)$ at follow-up. Eleven $(34.4 \%)$ patients were classified as having mild depressive symptoms, 16 (50\%) moderate and 5 (15.6\%) severe. Of those 81 patients, with no history of mental health issues, $35(43.2 \%)$ developed symptoms of anxiety and $24(29.6 \%)$ developed symptoms of depression.

\section{Health-related quality of life}

The median HUS in this cohort was 0.648 (IQR:0.406$0.823)$ and the median VAS $70(10-100) ; 87(93.5 \%)$ patients experienced one or more problem in any EQ-5D-5L domain (table 2). At the time of follow-up, 49
Table 2 Breakdown of patient EQ-5D-5L domains and anatomical sites of pain described via the BPI (COVID-19 cohort)

\begin{tabular}{|c|c|}
\hline Outcome characteristic & $\mathrm{n}=93$ \\
\hline \multicolumn{2}{|l|}{ EQ-5D-5L } \\
\hline \multicolumn{2}{|l|}{ EQ-5D-5L: mobility } \\
\hline No problem & $44(47.3)$ \\
\hline Slight problem & $12(12.9)$ \\
\hline Moderate problem & $22(23.7)$ \\
\hline Severe problem & $15(16.1)$ \\
\hline Extreme problem & $0(0)$ \\
\hline \multicolumn{2}{|l|}{ EQ-5D-5L: self-care } \\
\hline No problem & $66(71)$ \\
\hline Slight problem & $14(15)$ \\
\hline Moderate problem & $9(9.7)$ \\
\hline Severe problem & $4(4.3)$ \\
\hline Extreme problem & $0(0)$ \\
\hline \multicolumn{2}{|l|}{ EQ-5D-5L: usual activities } \\
\hline No problem & $25(26.8)$ \\
\hline Slight problem & $24(25.8)$ \\
\hline Moderate problem & $29(31.2)$ \\
\hline Severe problem & $13(14)$ \\
\hline Extreme problem & $2(2.2)$ \\
\hline \multicolumn{2}{|l|}{ EQ-5D-5L: pain/discomfort } \\
\hline No problem & $27(29.1)$ \\
\hline Slight problem & $19(20.4)$ \\
\hline Moderate problem & $24(25.8)$ \\
\hline Severe problem & $20(21.5)$ \\
\hline Extreme problem & $3(3.2)$ \\
\hline \multicolumn{2}{|c|}{ EQ-5D-5L: anxiety/depression } \\
\hline No problem & $33(35.5)$ \\
\hline Slight problem & $22(23.7)$ \\
\hline Moderate problem & $19(20.4)$ \\
\hline Severe problem & $15(16.1)$ \\
\hline Extreme problem & $4(4.3)$ \\
\hline \multicolumn{2}{|l|}{$\mathrm{BPI}^{*}$} \\
\hline \multicolumn{2}{|l|}{ Pain location from BPI } \\
\hline Head/neck & 8 \\
\hline Anterior trunk & 18 \\
\hline Back & 20 \\
\hline Arms & 26 \\
\hline Legs & 38 \\
\hline
\end{tabular}

*Sixty-five patients described pain via the BPI. Patients could describe more than one site of pain. $\mathrm{BPI}$, Brief Pain Inventory.

(52.7\%) patients described problems with mobility, with $37(75.5 \%)$ of these patients describing these mobility problems as either moderate or extreme. Twenty-seven (29\%) patients had problems with self-care activities and $68(73.1 \%)$ had problems carrying out usual activities, such as work and housework. Patients were asked about 


\begin{tabular}{|c|c|c|c|c|c|c|}
\hline \multirow[b]{2}{*}{ Characteristic/outcome } & \multicolumn{3}{|l|}{ Pre-matching } & \multicolumn{3}{|l|}{ Post-matching } \\
\hline & Non-COVID-19 & COVID-19 & $P$ value & Non-COVID-19 & COVID-19 & $P$ value \\
\hline No of patients & 206 & 93 & & 91 & 91 & \\
\hline Age, median (IQR), years & $58.2(50-65.7)$ & $59(54-67)$ & 0.11 & $59.3(52.5-66.7)$ & $60(54-67)$ & 0.74 \\
\hline Gender, male (\%) & $112(54.6)$ & $61(65.6)$ & 0.08 & $56(61.5)$ & $61(67)$ & 0.44 \\
\hline Follow-up time, days, median, (IQR) & $144(96-181)$ & $113(84-156)$ & 0.05 & $118(86-166)$ & $142(94-180)$ & 0.21 \\
\hline $\begin{array}{l}\text { Documented obesity on admission, } \\
\text { no (\%) }\end{array}$ & $50(24.4)$ & $30(32.3)$ & 0.16 & $24(26.4)$ & 29 (31.9) & 0.41 \\
\hline $\begin{array}{l}\text { Prescence of } 2 \text { of multimorbidity (two } \\
\text { or more comorbidities) (\%) }\end{array}$ & $64(31.2)$ & $47(51.1)$ & $<0.01$ & $32(35.2)$ & $45(50)$ & 0.12 \\
\hline $\begin{array}{l}\text { Mental Health problems pre-ICU, no } \\
(\%)\end{array}$ & $68(33.2)$ & $12(12.9)$ & $<0.01$ & $15(16.5)$ & $11(12.1)$ & 0.40 \\
\hline $\begin{array}{l}\text { Critical Care Length of stay, median } \\
\text { (IQR) days }\end{array}$ & $11.6(5-25.3)$ & $11.1(5-25.3)$ & 0.67 & $12.8(7-23.7)$ & $11.1(5-25.8)$ & 0.21 \\
\hline APACHE II, median (IQR) & $20(15-25)$ & $15(10-20)$ & $<0.01$ & $17(13-20.1)$ & $16(12-19)$ & 0.08 \\
\hline $\begin{array}{l}\text { Socioeconomic status (SIMD } \\
\text { category) }\end{array}$ & & & 0.13 & & & 0.71 \\
\hline 1 (most deprived) & $83(40.5)$ & $29(31.5)$ & & $33(36.2)$ & $28(31.1)$ & \\
\hline 2 & $50(24.4)$ & $19(20.7)$ & & $16(17.6)$ & $19(21.1)$ & \\
\hline 3 & $31(15.1)$ & $20(21.7)$ & & $21(23.1)$ & $20(22.2)$ & \\
\hline 4 & $22(10.7)$ & $8(8.7)$ & & $10(11)$ & $7(7.8)$ & \\
\hline 5 & $19(9.3)$ & $16(17.4)$ & & $11(12.1)$ & $16(17.8)$ & \\
\hline
\end{tabular}

APACHE II, Acute Physiology and Chronic Health Evaluation II ; SIMD, Scottish Index of Multiple Deprivation.

ongoing breathlessness and fatigue: $73(78.5 \%)$ reported ongoing breathlessness (at rest or on exertion) and 65 $(69.9 \%)$ described fatigue.

We undertook a predefined subgroup analysis to explore the HRQoL $(n=67)$ in those patients who were employed before the critical care admission $(n=67)$. Those who returned to employment had significantly higher HRQoL measured via the VAS (70 (IQR: 54.287.9 vs 60 (IQR: $31.7-70$ ), $\mathrm{p}=0.01$ ), in comparison to those patients who did not return to employment.

\section{Pain}

Sixty-five $(69.9 \%)$ patients described new pain since discharge from hospital via the BPI, most commonly reported in legs and arms. The distribution of anatomical regions where patients experienced pain is shown in table 2. Pain intensity at its worst in the previous 24 hours, measured via a scale of $0-10(0=$ no pain, $10=$ pain as bad as you can imagine), was more than or equal to 7 , in $27(41.5 \%)$ patients (representing severe pain). Pain on average, measured using the same scale, was a median of 5 (IQR: 3-6) across all 65 patients with pain. Almost two-thirds $(64.6 \%)$ of the patients who reported new pain following severe COVID-19 infection, were taking regular analgesia. Of the patients who had ongoing pain, $61(94 \%)$ patients reported that this pain interfered with aspects of their life such as sleep $(80 \%)$, mood $(66.2 \%)$ and relations with other people $(47.7 \%)$.
Propensity score matching: COVID-19 cohort versus nonCOVID-19 cohort outcomes

Employment, fatigue and breathlessness data was not collected for the non-COVID-19 cohort and thus is not included in the propensity score match analysis.

In total, we matched $91(97.8 \%)$ of the COVID-19 cohort with 91 non-COVID-19 critically ill patients (nonCOVID-19 cohort), who attended follow-up. Baseline demographics of the cohorts, pre and post matching, are shown in table 3 . There was no significant difference in any outcome measured between the two patient cohorts (COVID-19 vs non-COVID-19 cohorts) in the adjusted analysis (figure 4). Full outputs of the unadjusted and adjusted analysis are shown in online supplemental file S6.

\section{DISCUSSION}

This multicentre study has revealed that survivors of severe COVID-19 infection experience longer-term physical, emotional and social problems. To our knowledge, this is the first study which has described the outcomes of severe COVID-19 survivors in relation to non-COVID-19, critical care survivors. In this study, those patients who have been critically unwell due to COVID-19 appear to have similar outcomes to other ICU survivor cohorts. ${ }^{24} 25$ The high levels of new unemployment seen in the post hospital discharge period are also common in ICU survivors. ${ }^{26}$ In the context of the COVID-19 pandemic, new 
(A)

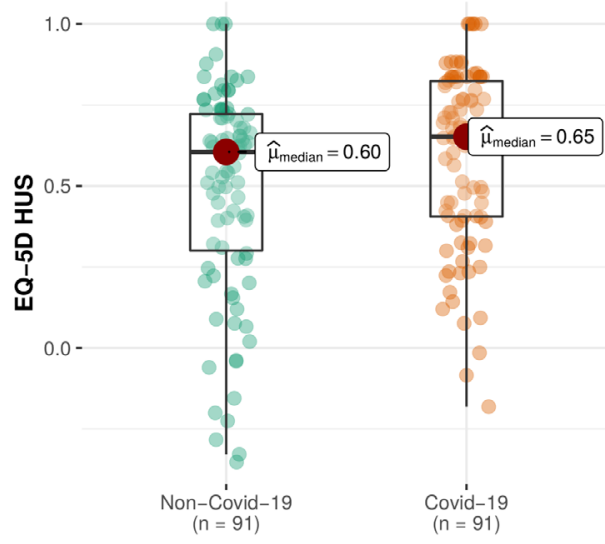

(C)

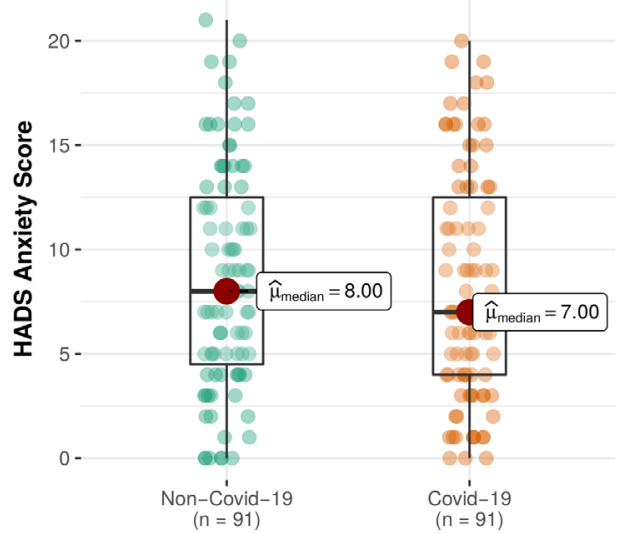

(B)

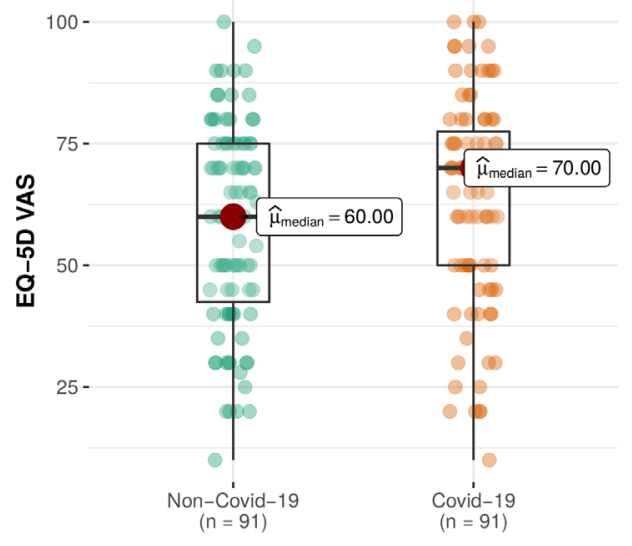

(D)

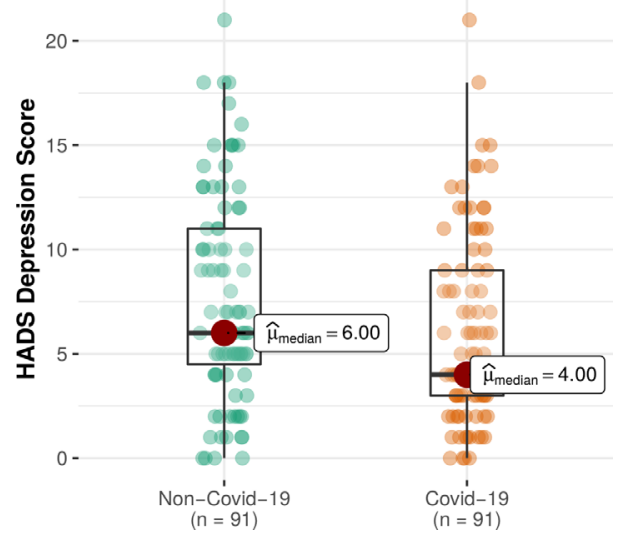

Figure 4 Distribution of EQ-5D (HUS) (A) EQ-5D VAS (B) HADS anxiety (C) and HADS depression (D) across the COVID-19 and the non-COVID-19 cohorts. HADS, Hospital Anxiety and Depression Score; HUS, Health Utility Score; VAS, Visual Analogue Scale.

unemployment is likely to be multifactorial and not solely related to new onset frailty or ill health. However, its distribution across the socioeconomic gradient is worrying.

The disproportionate impact of COVID-19 on the most deprived communities has been described previously. Those from socioeconomically deprived areas are more likely to develop COVID-19 and die from the disease. $^{2327}$ This study suggests that there may also be worse long-term outcomes for people from the most deprived communities. Although return to employment may not be viewed as a traditional health metric, societal factors outside healthcare undoubtedly contribute to health. ${ }^{28}$ Previous global events such as the 2008 financial crisis, led to a deterioration in population-level mental health. ${ }^{29}$ It is essential policy makers, alongside healthcare providers, ensure all is done to maximise outcomes for those most at risk, by ensuring sufficient social and economic security. ${ }^{30-32}$

Over two-thirds of patients in this cohort reported new onset pain following severe COVID-19 infection, a prevalence consistent with previous critical care research and the non-COVID-19 cohort examined in this study. ${ }^{33}$ Patients described this pain, in many cases as severe, regularly interfering with different aspects of activities of daily living. More work which examines the mechanisms driving this reported pain is required.

The results of this study demonstrate that structured multidisciplinary rehabilitation after severe illness, cannot be viewed as a luxury. Standardised rehabilitation pathways which aim to improve global HRQoL should be universally implemented. For those who cannot return to work, structured, cohesive vocational rehabilitation should be provided to ensure that those recovering have purposeful and meaningful activity. Those currently designing treatment pathways for COVID-19 must ensure that rehabilitation is not only multidisciplinary, but also multiagency, crossing health and social care boundaries. ${ }^{34}$

\section{LIMITATIONS}

This study has limitations inherent in most follow-up studies in this field. Epidemiological studies have demonstrated that there is a high level of anxiety at a population level due to the ongoing pandemic; these factors could have influenced the emotional outcomes reported in the COVID-19 cohort. $^{33}$ Moreover, we have limited data on patient mental health status before the pandemic. As such, some of the problems detailed in this analysis 
may not be related to the critical care experience. The decreased employment figures shown are also likely to be multifactorial, due to the high levels of unemployment internationally. We also have no information on plans to return to employment, or data on job seeking intention. Additionally, we only have data at one time point; the recovery trajectory for each individual participant is likely to be variable. Longitudinal work which examines the dynamics of these outcomes is needed. Moreover, employment, breathlessness and fatigue data were not available for the non-COVID-19 cohort.

We recognise that our use of a historical control has limitations. Moreover, although both patient cohorts attended the same recovery programme, the societal changes and the social support available during the COVID-19 pandemic, were distinctly different and may have influenced the results reported.

We specifically sought to understand new pain since the COVID-19 illness; however, patients may have reported pre-existing problems or the exacerbation of previous aliments. Although we have basic baseline data about those who did not attend the clinic, this works lacks detailed information about this group. Those who did not attend InS:PIRE, could have had a different recovery experience. Finally, due to the small sample size, caution must be taken when interpreting these results. This analysis requires replication with a larger patient population.

\section{CONCLUSIONS}

In conclusion, patients who have been severely ill due to COVID-19 experience similar problems to other ICU survivors after discharge. In this multicentre study, lower numbers of patients from socioeconomically deprived areas returned to work following severe COVID-19, compared with their more affluent counterparts. This study highlights the need for multifaceted rehabilitation, which focuses on all aspects of health and well-being.

Contributors JM and TQ: conceptualisation of the study. JM, PH and MS conducted the analysis (formal analysis). JM, MS, TQ, SS contributed to the interpretation of the findings (validation). JM acts as the overall guarantor. All authors critically revised the paper for intellectual content and approved the final version of the manuscript.

Funding THIS. Institute (University of Cambridge) (PD-2019-02-16).

Competing interests None declared.

Patient consent for publication Not applicable.

Ethics approval This study involves human participants and was approved by Ethical approval was granted by the Liverpool Central Research Ethics Committee (Reference Number: 17/NM/0199).

Provenance and peer review Not commissioned; externally peer reviewed.

Data availability statement Data are available on reasonable request. The datasets used and/or analysed during the current study are available from the corresponding author on reasonable request.

Supplemental material This content has been supplied by the author(s). It has not been vetted by BMJ Publishing Group Limited (BMJ) and may not have been peer-reviewed. Any opinions or recommendations discussed are solely those of the author(s) and are not endorsed by BMJ. BMJ disclaims all liability and responsibility arising from any reliance placed on the content. Where the content includes any translated material, BMJ does not warrant the accuracy and reliability of the translations (including but not limited to local regulations, clinical guidelines, terminology, drug names and drug dosages), and is not responsible for any error and/or omissions arising from translation and adaptation or otherwise.

Open access This is an open access article distributed in accordance with the Creative Commons Attribution 4.0 Unported (CC BY 4.0) license, which permits others to copy, redistribute, remix, transform and build upon this work for any purpose, provided the original work is properly cited, a link to the licence is given, and indication of whether changes were made. See: https://creativecommons.org/ licenses/by/4.0/.

ORCID iD

Joanne McPeake http://orcid.org/0000-0001-8206-6801

\section{REFERENCES}

1 Intensive Care National Audit and Research Centre. ICNARC report on COVID-19 in critical care, 2020. Available: https://www.icnarc. org/Our-Audit/Audits/Cmp/Reports [Accessed 29 Dec 2020].

2 Docherty AB, Harrison EM, Green CA, et al. Features of 20133 UK patients in hospital with covid-19 using the ISARIC WHO Clinical Characterisation Protocol: prospective observational cohort study. BMJ 2020;369:m1985.

3 Richardson S, Hirsch JS, Narasimhan M, et al. Presenting characteristics, comorbidities, and outcomes among 5700 patients hospitalized with COVID-19 in the new York City area. JAMA 2020;323:2052-9.

4 Karaglannidis C, Mostert C, Hentschker C. Case characteristics, resource use and outcomes of 10021 patients with COVID-19 admitted to 920 German hospitals: an observational study. Lancet Respiratory Medicine 2020;8.

5 Coulter A, Richards T. Care during covid-19 must be humane and person centred. BMJ 2020;370:m3483.

6 Sasangohar F, Dhala A, Zheng F, et al. Use of telecritical care for family visitation to ICU during the COVID-19 pandemic: an interview study and sentiment analysis. BMJ Qual Saf 2021;30:1-7.

7 McPeake J, Iwashyna TJ, Henderson P, et al. Long term outcomes following critical care hospital admission: a prospective cohort study of UK biobank participants. Lancet Reg Health Eur 2021;6:100121.

8 Herridge MS, Cheung AM, Tansey CM, et al. One-Year outcomes in survivors of the acute respiratory distress syndrome. New England Journal of Medicine 2003;348:683-93.

9 Pandharipande PP, Girard TD, Jackson JC, et al. Long-Term cognitive impairment after critical illness. New England Journal of Medicine 2013;369:1306-16.

10 Wade DM, Howell DC, Weinman JA, et al. Investigating risk factors for psychological morbidity three months after intensive care: a prospective cohort study. Critical Care 2012;16:R192.

11 Mikkelsen ME, Still M, Anderson BJ, et al. Society of critical care medicine's international consensus conference on prediction and identification of long-term impairments after critical illness. Crit Care Med 2020;48:1670-9.

12 Sevin CM, Boehm LM, Hibbert E, et al. Optimizing critical illness recovery: perspectives and solutions from the caregivers of ICU survivors. Crit Care Explor 2021;3:e0420.

13 Johnson CC, Suchyta MR, Darowski ES, et al. Psychological sequelae in family caregivers of critically III intensive care unit patients. A systematic review. Ann Am Thorac Soc 2019;16:894-909.

14 von Elm E, Altman DG, Egger M, et al. Strengthening the reporting of observational studies in epidemiology (STROBE) statement: guidelines for reporting observational studies. BMJ 2007;335:806-8.

15 Intensive Care Society. Levels of critical care for adult patients. The intensive care Society. London; 2009.

16 McPeake J, Iwashyna TJ, Devine H, et al. Peer support to improve recovery following critical care discharge: a case-based discussion. Thorax 2017;72:856-8.

17 MacTavish P, Quasim T, Purdie C, et al. Medication-Related problems in intensive care unit survivors: learning from a multicenter program. Ann Am Thorac Soc 2020;17:1326-9.

18 Scottish Government. Scottish index of multiple deprivation 2020, 2020. Available: https://www.scotlandscensus.gov.uk/variablesclassification/ethnic-group [Accessed 14 Dec 2020].

19 Szende A, Oppe M, Devlin N. EQ-5D value sets: inventory and comparative review and user guide. Netherlands Springer; 2006.

20 Zigmond AS, Snaith RP. The hospital anxiety and depression scale. Acta Psychiatr Scand 1983;67:361-70.

21 Needham DM, Sepulveda KA, Dinglas VD, et al. Core outcome measures for clinical research in acute respiratory failure survivors. An international modified Delphi consensus study. Am J Respir Crit Care Med 2017;196:1122-30. 
22 Cleeland CS. The brief pain inventory user guide, 2009. Available: https://www. mdanderson.org/documents/Departments-andDivisions/ Symptom-Research/BPI_UserGuide.pdf [Accessed 15 Dec 2020].

23 Lone NI, McPeake J, Stewart NI, et al. Influence of socioeconomic deprivation on interventions and outcomes for patients admitted with COVID-19 to critical care units in Scotland: a national cohort study. Lancet Reg Health Eur 2021;1:100005.

24 Rabiee A, Nikayin S, Hashem MD, et al. Depressive symptoms after critical illness: a systematic review and meta-analysis. Crit Care Med 2016;44:1744-53.

25 Nikayin S, Rabiee A, Hashem MD, et al. Anxiety symptoms in survivors of critical illness: a systematic review and meta-analysis. Gen Hosp Psychiatry 2016;43:23-9.

26 McPeake J, Mikkelsen ME, Quasim T, et al. Return to employment after critical illness and its association with psychosocial outcomes. A systematic review and meta-analysis. Ann Am Thorac Soc 2019;16:1304-11.

27 Office for National Statistics. Death involving COVID-19 by local area and socioeconomic deprivation: deaths occurring between 1 March and 17 April 2020, 2020. Available: https://www.ons.gov.uk/ peoplepopulationandcommunity/birthsdeathsandmarriages/deaths/ bulletins/deathsinvolvingcovid19bylocalareasanddeprivation/deat hsoccurringbetween1marchand17april [Accessed 4 Aug 2020].
28 Berwick DM. The moral determinants of health. JAMA 2020;324:225-6.

29 Parmar D, Stavropoulou C, loannidis JPA. Health outcomes during the 2008 financial crisis in Europe: systematic literature review. BMJ 2016;354:i4588.

30 Anderson G, Frank JW, Naylor CD, et al. Using socioeconomics to counter health disparities arising from the covid-19 pandemic. BMJ 2020;369:m2149.

31 McPeake JH, MacTavish P, et al. Provision of holistic care after severe COVID-19 pneumonia: integrating health and social care services. Lancet Respiratory Medicine 2021;9.

32 Parker AM, Brigham E, Connolly B, et al. Addressing the post-acute sequelae of SARS-CoV-2 infection: a multidisciplinary model of care. Lancet Respir Med 2021;9:1328-41.

33 Devine H, Quasim T, McPeake J, et al. Chronic pain in intensive care unit survivors: incidence, characteristics and side-effects up to oneyear post-discharge. J Rehabil Med 2019;51:451-5

34 Pan K-Y, Kok AAL, Eikelenboom M, et al. The mental health impact of the COVID-19 pandemic on people with and without depressive, anxiety, or obsessive-compulsive disorders: a longitudinal study of three Dutch case-control cohorts. Lancet Psychiatry 2021;8:121129 